\title{
Experimental analysis of first foul flush in an industrial area
}

\author{
S. Artina ${ }^{1}$, A. Bolognesi ${ }^{1}$, T. Liserra ${ }^{1}$, M. Maglionico ${ }^{1}$ \\ \& G. Salmoiraghi ${ }^{2}$ \\ ${ }^{1}$ DISTART - Università di Bologna, Italy \\ ${ }^{2}$ Dipartimento di Biologia Evoluzionistica Sperimentale - Università di \\ Bologna, Italy
}

\begin{abstract}
This paper is about a monitoring study carried out in a commercial-industrial site near Bologna (Italy). The experimental activity aims to determine a suitable relationship between single pollutant components and the hydrological response of catchment related to this specific kind of anthropic activity. The experimental catchment is part of a stocking area, run over every day by several trucks. The watershed area is about 1.15 ha, almost completely impermeable, including a parking area and charge-discharge zone for trucks and also a small part of the warehouse building roofs. Storm water is collected by a small drainage system into a first foul flush tank, whose useful volume is about $36 \mathrm{~m}^{3}$. In order to study both hydraulic and water quality aspects, the site has been equipped with several instruments, like an automatic sampler, rainfall gauge, submerged level sensor, turbidity meter and a multiparametric probe. Rainfall data, tank water level and turbidity have been recorded continuously for 8 months; during that period 57 rainfall events $(>1 \mathrm{~mm}$ ) have taken place (total rainfall of $451 \mathrm{~mm}$ ). For five of those events, samples were collected and analyzed obtaining TSS, COD, heavy metals, toxicity and other parameters concentration. Results obtained from the acute toxicity tests, carried out with Vibrio Fischeri on water samples collected have exhibited some particular effects caused by the bio-ecological conditions of runoff stormwater. An important issue comes from the lack of a clear linear correlation between organic, inorganic pollutants and the toxicity percentage.

Keywords: experimental catchment, first flush, total suspended solids, toxicity, turbidity.
\end{abstract}




\section{Introduction}

Stormwater management is nowadays a fundamental component within the environmental protection of receiving water bodies [4]. In many cases in fact, pollutant concentrations or mass emissions at the onset of rainfall, usually called "first foul flush", exceed those from wastewater treatment plants. However in order to find a kind of optimal management of those first flush flows, it is necessary to improve our knowledge on stormwater runoff components $[3,5,7$, 8] and processes, related to land uses, hydrological [6] and morphological factors. This paper describes operational phases and main results of an environmental monitoring activity that has taken place in a first flush tank, located in a heavily trafficked commercial-industrial area. Therefore high vehicular activity leads to high build-up rate of pollutants during dry weather periods, which involve road pavement deterioration, tire and mechanical parts consumption, as well as fuel and lubrificant deposition above the surface area. The experimental survey has tried to establish possible relationships between chemical-biological laboratory results and hydrological values recorded in place as well as to show the presence of first flush in charge-discharge areas.

\section{The experimental site}

The catchment is part of a warehouse area constituted by two parking and transit store-yards (about $1 \mathrm{ha}$ ) for long vehicles and also by a large warehouse building where the goods carried by trucks are temporally stored and then re-distributed to many department stores spread all across northern Italy. Therefore a large number of long vehicles (daily average of 200) moves and stands on the catchment surface. The tank drains also a small portion of the warehouse roof (about $0.16 \mathrm{ha}$ ), but does not receive any domestic waste water. Rainwater is drained by a small drainage network and then delivered to the tank through 3 main circular concrete conduits. The effective volume is strictly dependent on the invert level of the two outlet devices (overflow and bottom outlet). The nominal volume of the tank should be $48 \mathrm{~m}^{3}$, but since the bottom outlet's invert level creates a sort of dead volume, the effective volume reduces itself to $36 \mathrm{~m}^{3}$ (see figure 1).

\section{Installed instruments}

In order to record hydraulic and water quality data, several instruments have been installed inside the tank: a rain gauge, an automatic sampler, a submerged level meter, a turbidity sensor and, in a later phase, a multiparameter probe.

The rain gauge is a tipping bucket "ISCO 674" model, with a sensibility of $0.1 \mathrm{~mm}$, whose reliability up to $200 \mathrm{~mm} / \mathrm{h}$ has been previously tested in laboratory. Stormwater samples have been collected through the "ISCO 6712" automatic sampler. It contains 24 bottles of 1 litre size, which can be filled at fixed intervals. The submerged level meter has been placed on the bottom of the 
tank, it uses a differential pressure transducer to measure water depth. The depth meter and the rain gauge are both connected to the sampler controller, which can collect and store data with a time step of 1 minute.

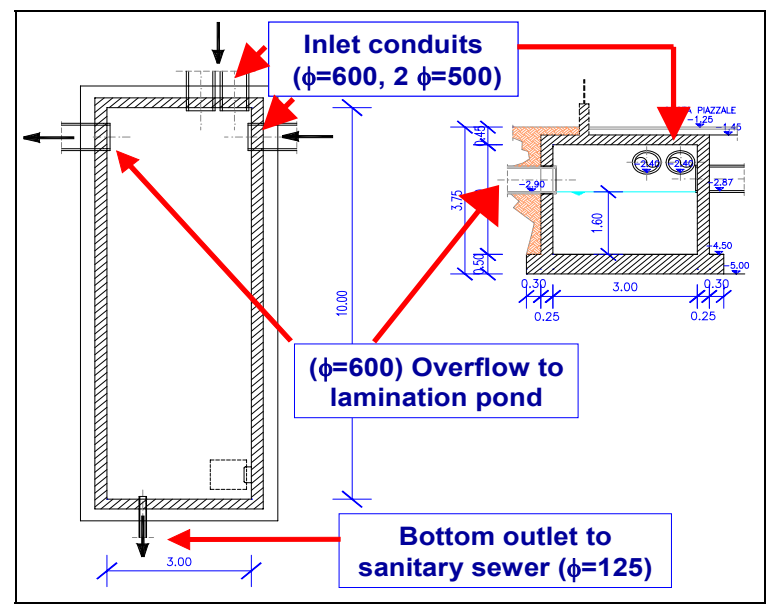

Figure 1: $\quad$ Plan view and cross-sectional scheme of the tank.

The collecting sequence activation has been based either on water level reached inside the tank or on rainfall intensity value. The turbidity meter is made of two different instruments: the measurement probe "Endress+Hauser CUS 41" connected to its own controller and a further device necessary to store data measured by the probe. The multiparameter "In-Situ Troll 9000 XP" is a probe capable of measuring and logging data for many parameters simultaneously, like $\mathrm{pH}$, turbidity, water depth, conductivity with a time step of 20 seconds. Since no electric grid was available nearby, electric power has been supplied to the instruments through a high capacity (200 Ah) $12 \mathrm{~V}$ battery. Devices working with alternating current have required the presence of an inverter.

\section{Data collection}

Different working conditions of the installed instruments have taken place during the 8 months monitoring activity, depending on practical problems and also on information coming from observed data. Those different experimental setups have been schematized in four temporally ordered phases, which cover the whole period of investigation and therefore include all the five events for which chemical analysis of samples were made.

First phase: after the bottom of the tank was cleared removing the dead water volume and the accumulated sediments, the water depth meter probe; the turbidity meter probe and the sampler collecting probe were placed on the bottom of the tank. The sampler has been then programmed in order to start its collecting sequence when a fixed water level was reached inside the tank. Through this configuration Event 1 was sampled (figure 4). 
Second phase: as the bottom outlet seemed not to work properly, an opening controller device was applied to the $125 \mathrm{~mm}$ conduit in order to reduce uncertainties. No changes have been made to the instruments placed inside the tank during the first phase. This configuration regards Event 2 (figure 5).

Third phase: as the main interesting parameter observed were turbidity and water level inside the tank, a new instrument (Troll 9000 XP) capable of measuring both level and turbidity was placed next to the existing ones. The purpose was to test the new probe itself and analyze how the same kind of parameter, collected in the same place, by different instruments, could compare. The comparison between turbidity meters exhibited remarkable differences as shown in figure 2.

Fourth phase: analysing data from the first three phases it was quite clear that the dead volume of water always present inside the tank had negative effect on the first flush pollutant load investigation. In fact, during dry weather periods, still water strongly increases settling on the bottom of the tank. Therefore when a new rainfall occurs, the effect (in terms of turbidity) of re-suspension becomes more relevant than the one produced by the pollutant load flowing into the tank. This problem suggested moving the multiparameter and the sampler probes to the main inlet conduit ( $600 \mathrm{~mm}$ diameter) in order to be able to measure directly depth and turbidity of stormwater flowing into the tank. The multiparameter has been chosen due to its capability of measuring both parameters with a single instrument and also because of the higher reliability exhibited by its turbidity meter. In order to obtain discharge values from water depth data, a special weir, whose rating curve had previously been found in laboratory, has been applied to the downstream end of the conduit. Since the multiparameter Troll 9000 cannot be connected to the sampler controller, the sampling activation time has been based on rainfall intensity value. Events 3, 4 and 5 have been collected through this last experimental configuration (figures 6-8).

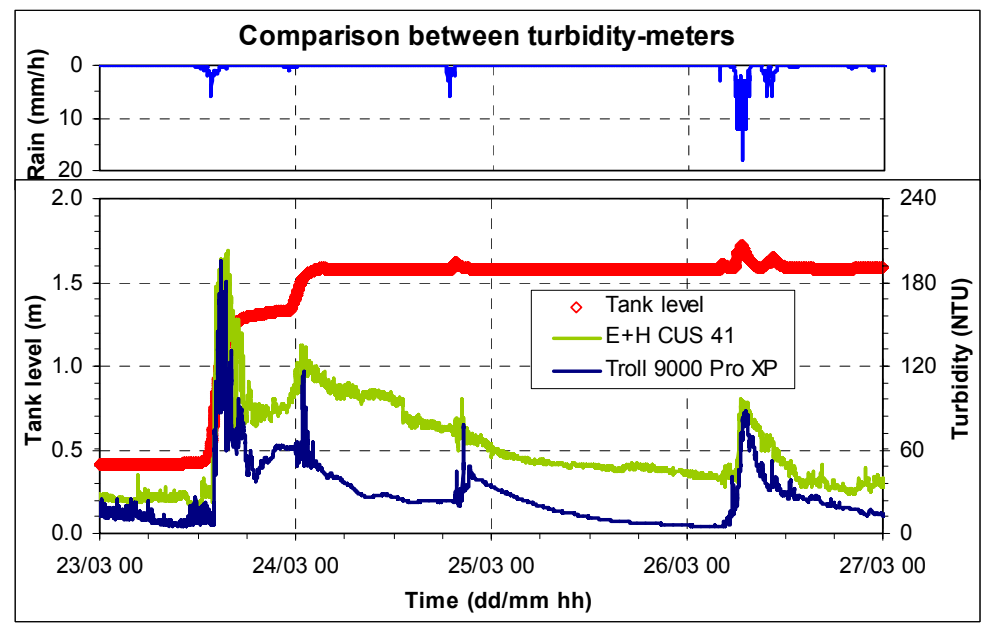

Figure 2: $\quad$ Comparison between turbidity meters. 


\section{Analysis of sampled and measured data}

Rainfall data have been collected from the end of November 2003 to the end of July 2004. During that period 57 rainfall events $(>1 \mathrm{~mm})$ have taken place giving a total rainfall amount of $451 \mathrm{~mm}$ (figure 3 ). Since the monitoring activity went through different seasons, rainfall intensity has shown very variable values, ranging from less than $1 \mathrm{~mm} / \mathrm{h}$ to a $66 \mathrm{~mm} / \mathrm{h}$ peak.

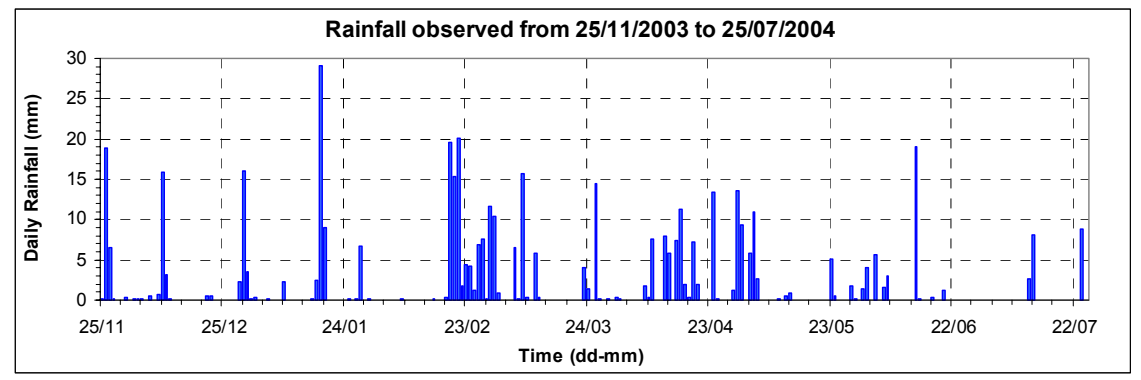

Figure 3: Daily rainfall recorded during the entire monitoring period.

\subsection{Sampled events}

Results obtained from sampling and hydrologic data collection are reported in the following graphs. Each of them represents one of the five events already mentioned in the previous paragraphs. Numerical mean results are instead presented in Table 1. Turbidity and TSS, COD concentration plots have been normalized to their maximum value.

As shown in figures 4 and 5, very low rainfall intensity observed during event 1 and 2 have increased delays due to initial losses and lowered the effects of surface wash-off and pollutant transport.

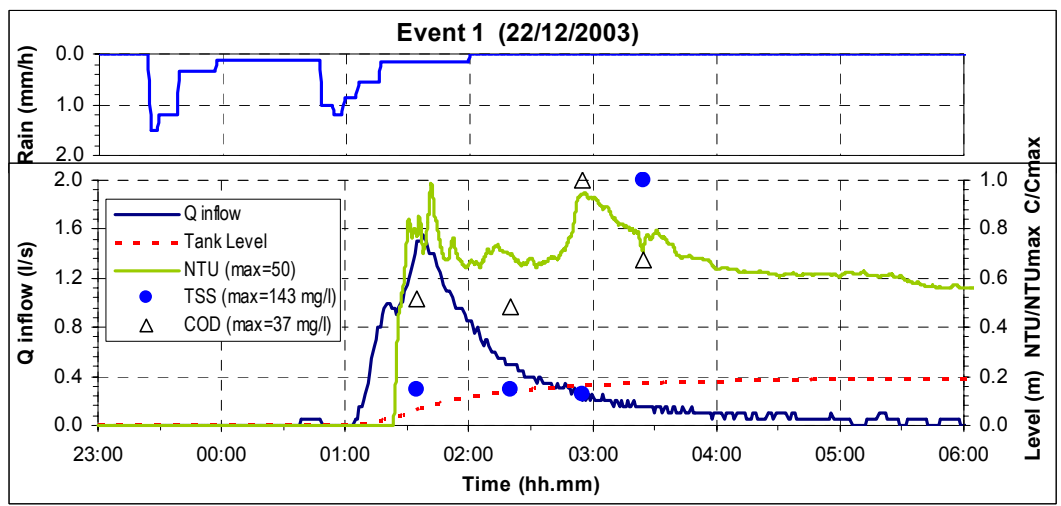

Figure 4: Event 1: rainfall intensity, tank level and inflow discharge; turbidity and TSS, COD concentration detected inside the tank. 


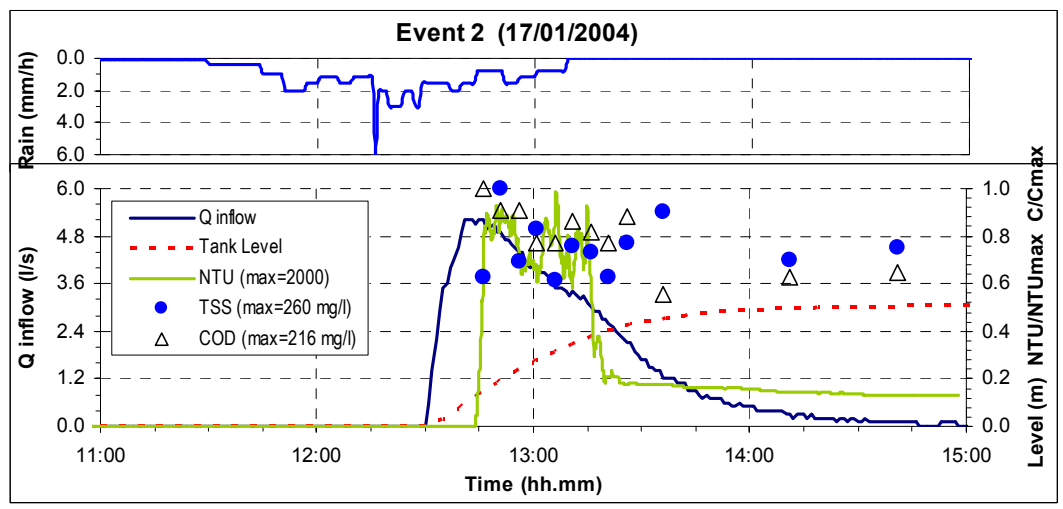

Figure 5: Event 2: rainfall intensity, tank level and inflow discharge; turbidity and TSS, COD concentration detected inside the tank.

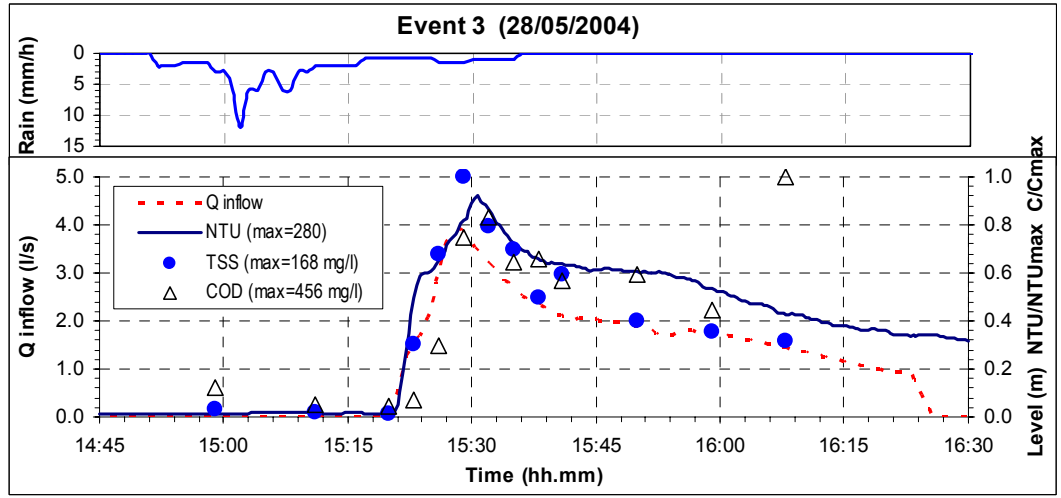

Figure 6: Event 3: rainfall intensity, inflow discharge; turbidity and COD, TSS concentration detected in the main inlet conduit.

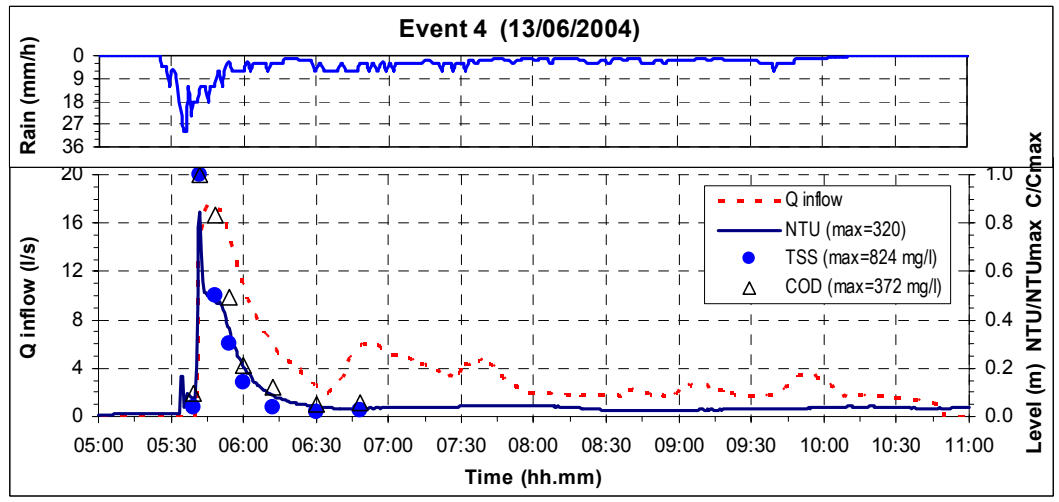

Figure 7: Event 4: rainfall intensity, inflow discharge; turbidity and COD, TSS concentration detected in the main inlet conduit. 


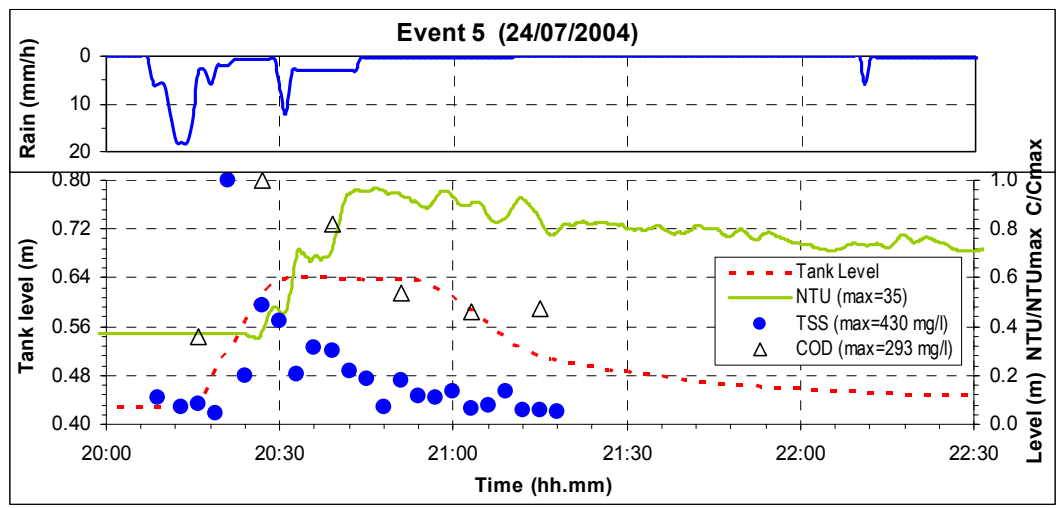

Figure 8: Event 5: rainfall intensity, tank level, turbidity inside the tank and COD, TSS concentration detected in the main inlet conduit.

Table 1: Hydrological parameters and Event Mean Concentrations (EMC) representative for the five sampled events.

\begin{tabular}{|l|c|c|c|c|c|}
\hline & Event 1 & Event 2 & Event 3 & Event 4 & Event 5 \\
\hline Total rainfall $(\mathrm{mm})$ & 1.1 & 2.3 & 1.8 & 17.5 & 3.1 \\
\hline Max intensity (mm/h) & 1.5 & 6 & 12 & 30 & 18 \\
\hline Dry weather period $(\mathrm{h})$ & 261 & 200 & 108 & 170 & 298 \\
\hline $\mathrm{SST}(\mathrm{mg} / \mathrm{l})$ & 143.0 & 196.0 & 94.8 & 258.8 & 88.4 \\
\hline $\mathrm{COD}(\mathrm{mg} / \mathrm{l})$ & 25.0 & 140.0 & 273.2 & 167.9 & 202.8 \\
\hline $\mathrm{SO}(\mathrm{mg} / \mathrm{l})$ & 192.00 & 24.30 & 28.57 & 10.04 & 24.07 \\
\hline $\mathrm{Cl}(\mathrm{mg} / \mathrm{l})$ & 18.40 & 16.00 & 7.77 & 1.86 & 12.69 \\
\hline $\mathrm{NO}(\mathrm{mg} / \mathrm{l})$ & 2.69 & 1.09 & 0.26 & 0.45 & 0.48 \\
\hline $\mathrm{Pb}(\mathrm{mg} / \mathrm{l})$ & 0.003 & 0.015 & 0.013 & 0.015 & 0.003 \\
\hline $\mathrm{Cu}(\mathrm{mg} / \mathrm{l})$ & 0.010 & 0.025 & 0.038 & 0.033 & 0.030 \\
\hline $\mathrm{Zn}(\mathrm{mg} / \mathrm{l})$ & 0.043 & 0.236 & 0.267 & 0.395 & 0.161 \\
\hline
\end{tabular}

\section{Discussion of results}

A strong correlation between some of the heavy metals sampled $(\mathrm{Pb}, \mathrm{Cu})$ and TSS concentration is shown in figure 9 and besides the well known dimensionless $\mathrm{M}(\mathrm{V})$ curves have been plotted (figure 10). These curves indicate the variation of the cumulative pollutant mass divided by the total pollutant mass in relation to the cumulative volume divided by the total volume [2].

Pollutant mass is here represented by TSS, and COD data. In figure 10 almost all the curves are quite above the bisector, showing therefore that the most part of pollutant mass occurs in the first part of the event, i.e. the "first flush" phenomenon. The "first flush" behaviour is quite clearly exhibited by event 4, which is anyway the one among those collected, for which the highest rainfall intensity has been recorded. 

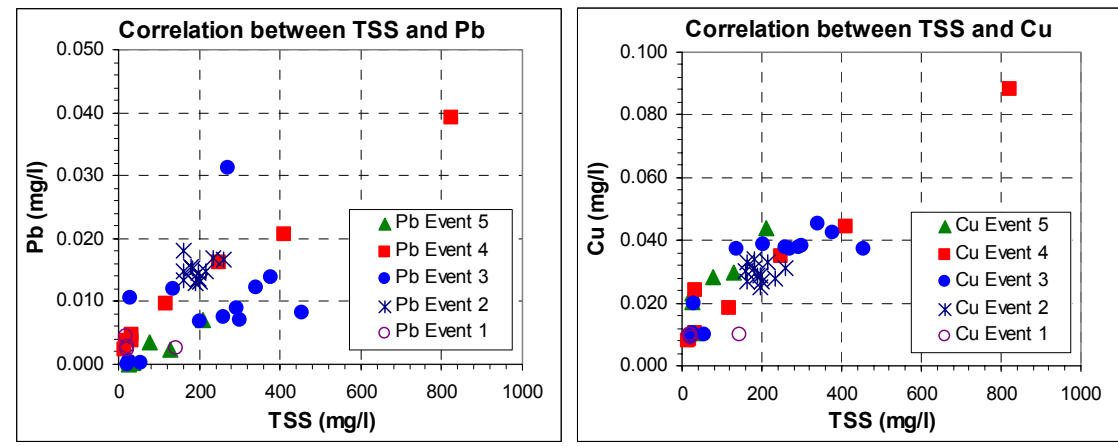

Figure 9: Correlations between TSS and $\mathrm{Pb}$ (left), $\mathrm{Cu}$ (right), for each event.
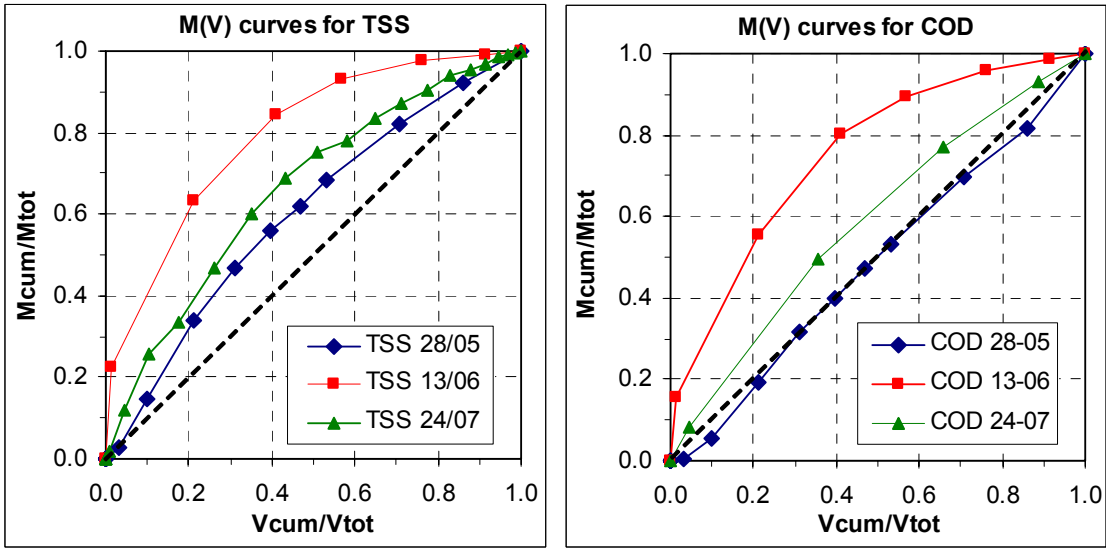

Figure 10: $\quad \mathrm{M}(\mathrm{V})$ curves for TSS (left), COD (right), for events 3, 4 and 5.

Results obtained from the acute toxicity tests, carried out with Vibrio fischeri [1] on water samples collected in the main inlet conduit and with a double reading (at 15 and at 30 minutes) of the inhibition percentage, have exhibited some particular effects caused by bio-ecological conditions of runoff stormwater. The first important issue is the lack of a clear linear correlation between organic, inorganic pollutants and the toxicity percentage. Relationships "cause-effect" between dissolved elements and toxicity are not evident and easy to detect, because they are always hidden by boundary conditions ( $\mathrm{pH}$, alkalinity, particulate, sediments, ecc.) due to the sinergy among different compounds.

It is quite clear instead that, basing on the Vibrio Fischeri test, sampled stormwater has to be considered partially toxic. This statement derives not only from the most critical condition outlined by maximum inhibition values observed during Event 4 (30\% at 30'), but also from what shown by all the other results, where maximum values range from $15 \%$ to $27 \%$. Another condition outlined by toxicity results, represented in figure 11, is a sort of "tail" of inhibition, which 
means the persistence of high inhibition values also when stormwater runoff has come to lower values. A possible explanation may be found in temporal delay between rainfall and runoff arrival time inside the tank.
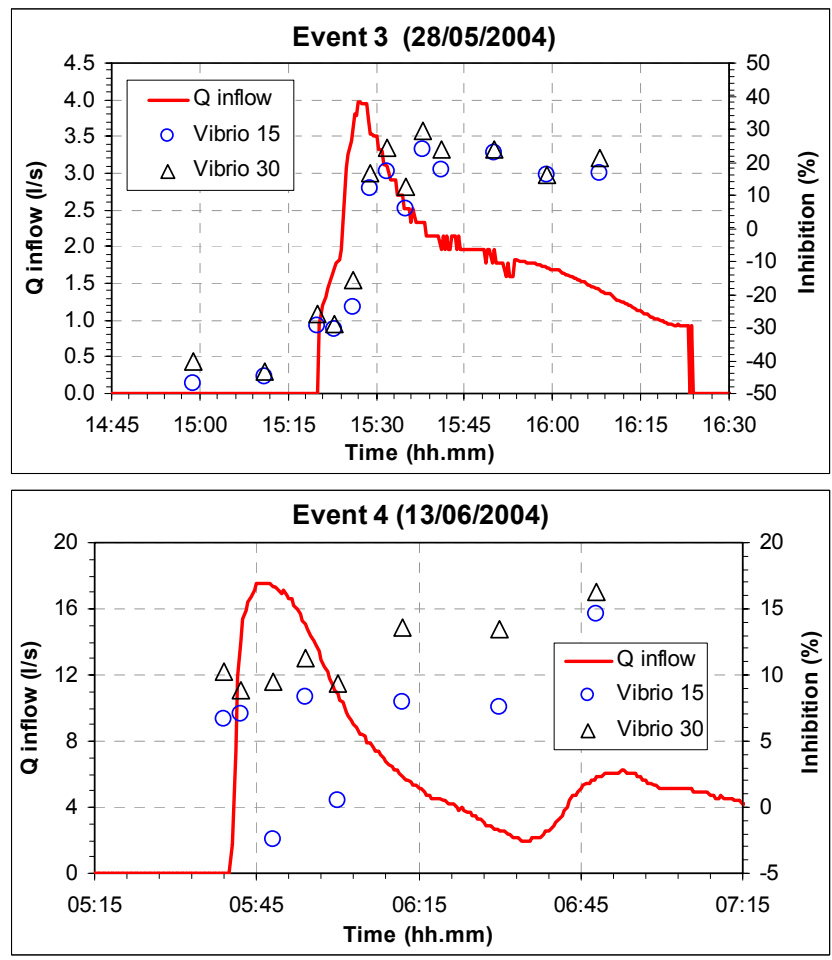

Figure 11: Toxicity test results: inhibition percentage of Vibrio Fischeri and inflow discharge rate for event 3 (top) and 4 (bottom).

\section{Conclusions}

From November 2003 to July 2004 an experimental survey has been carried out into a first flush tank near Bologna, northern Italy. Several data have been observed in order to analyze the first flush phenomenon for a small impervious watershed included in a heavily trafficked industrial area. Five rainfall-runoff events have been also examined through chemical and biological laboratory analysis of samples collected either inside the tank or in the main conduit flowing into it. A first flush has occurred for almost all the analyzed events, but it has also confirmed to depend on rainfall intensity value: an higher intensity leads to a more evident first flush behaviour. Furthermore, good correlations between TSS and heavy metals concentrations have been found, evidencing that the most part of pollutant is attached to the suspended solids. Interesting results have also come from the comparison between turbidity values and TSS 
concentrations. Turbidity values in fact follow the trend of TSS concentrations in terms of "curve shape", unfortunately it has not been possible to define a stable proportionality coefficient between them. Moreover, tests made on two different turbidity meters have shown that turbidity value depends sensibly on the instrument, in fact similar responses have been found in terms of temporal trends, but not in terms of absolute values, adding further uncertainty on reliable relationships between TSS and turbidity.

\section{Acknowledgements}

We'd like to thank: CICC (Anzola, Bologna) for allowing us to install instruments inside their area; laboratory CSA (Rimini) for the chemical analysis; IBAX for rent of multiparameter TROLL 9000 XP; Daniele Pagnani for his collaboration during the monitoring activity.

\section{References}

[1] APAT IRSA-CNR, 8030 Metodo valutazione della tossicità acuta con batteri bioluminescenti. Metodi analitici per le acque, Volume Terzo, 2003.

[2] Krajewski J.L., Chebbo G. and Saget A., Distribution of pollutant mass vs. volume in stormwater discharges and the first flush phenomenon. Water Research, 32(8), 2341-2356, 1998.

[3] Christina C.M. and Sansalone J.J., Kinematic Wave Model of Urban Pavement Rainfall-Runoff Subject to Traffic Loadings. J Environ Eng ASCE 129(7), 629-636, 2003.

[4] Deletic A., The first flush load of urban surface runoff. Water Research, 32(8), 2462-2470, 1998.

[5] Deletic A. and Maksimovic C.T., Evaluation of water quality factors in storm runoff from paved areas. J Environ Eng ASCE 124, 869-879, 1998.

[6] Gupta K. and Saul A.J., Specific relationships for the first flush load in combined sewer flows. Water Res 30, 1244-1252, 1996.

[7] Lee J.H. and Bang K.W., Characterization of urban stormwater runoff. Water Res 34, 1773-1780, 2000.

[8] Sansalone J.J. and Buchberger S.G., Partitioning and first flush of metals in urban roadway storm water. J Environ Eng ASCE 123, 134-143, 1997. 